Pirineos. Revista de Ecología de Montaña

Vol. 172

Jaca, Enero-Diciembre, 2017, e026

ISSN-L: 0373-2568

doi: http://dx.doi.org/10.3989/Pirineos.2017.172001

\title{
DESCUBRIMIENTO Y CARACTERIZACIÓN GEOGRÁFICA DE UNA DEPRESIÓN ULTRAMÁFICA EN SIERRA BERMEJA: NUEVOS DATOS GEOMORFOEDÁFICOS, FITOGEOGRÁFICOS Y PALEOECOLÓGICOS ${ }^{1}$
}

\author{
Discovery and geographical characterization of an ultramafic \\ depression in Bermeja Mountain: New geomorphological, soil, \\ vegetation and paleoecological data
}

\author{
José Gómez-Zotano ${ }^{1 *}$, José Antonio Olmedo-Cobo ${ }^{1}$, Raquel Cunill-Artigas², Emilio Martínez-Ibarra1 \\ ${ }^{1}$ Departamento de Análisis Geográfico Regional y Geografía Física, Universidad de Granada. 18071 Granada. \\ ${ }^{2}$ GRAMP, Departament de Geografia, Universitat Autònoma de Barcelona. 08193 Bellaterra, Cerdanyola del V. (Barcelona). \\ Identificador ORCID de los autores y e-mail: \\ José Gómez-Zotano: http://orcid.org/0000-0001-8692-9969. E-mail: jgzotano@ugr.es \\ José Antonio Olmedo-Cobo: http://orcid.org/0000-0002-4457-3594. E-mail: jaolmedo@ugr.es \\ Raquel Cunill-Artigas: http://orcid.org/0000-0002-4627-3632.E-mail: cunillraquel@gmail.com \\ Emilio Martínez-Ibarra: http://orcid.org/0000-0002-8987-1931. E-mail: emibarra@ugr.es \\ *Autor corresponsal.
}

\begin{abstract}
Recibido: 04-07-2016. Aceptado: 10-02-2017. Fecha de publicación on-line: 18/04/2017
Citation / Cómo citar este artículo: Gómez-Zotano, J., Olmedo-Cobo, J. A., Cunill-Artigas, R., Martínez-Ibarra, E (2017). Descubrimiento y caracterización geográfica de una depresión ultramáfica en Sierra Bermeja: nuevos datos geomorfoedáficos, fitogeográficos y paleoecológicos. Pirineos, 172, e026. doi: http://dx.doi.org/10.3989/Pirineos.2017.172001

RESUMEN: Se presenta el reciente hallazgo y caracterización preliminar de una cuenca endorreica en la cumbre de la Sierra Palmitera, una abrupta estribación del macizo peridotítico de Sierra Bermeja (SW de España) que alcanza 1.473 m.s.n.m. Dada la naturaleza ultramáfica de esta montaña litoral, dicha cuenca se considera una excepcionalidad geomorfológica para el conjunto de los afloramientos peridotíticos conocidos. El trabajo de campo y la interpretación de fotografías, principales procedimientos metodológicos de la investigación, así como el uso de un SIG, han permitido un reconocimiento geográfico inicial y el cartografiado de los principales rasgos físicos a escala de detalle (1: 5.000). Los resultados obtenidos son: (1) un mapa topográfico (equidistancia de curvas de nivel $5 \mathrm{~m}$ ) como base de la cartografía temática; (2) la identificación, caracterización y cartografiado a la escala señalada de las principales unidades geomorfo-edáficas; (3) la caracterización de la vegetación y la flora de la cuenca mediante el análisis fitosociológico, y el levantamiento de un mapa de vegetación a escala de detalle. Estos resultados arrojan luz a una serie de interrogantes en cuanto al origen de la cuenca, su funcionamiento y papel ecológico. Como rasgo sobresaliente, la acumulación de sedimentos en el fondo de la cuenca ha posibilitado el estudio paleo-ecológico de la vegetación a
\end{abstract}

\footnotetext{
${ }^{1}$ Este trabajo tiene su origen en una comunicación presentada en el XXIV Congreso de la Asociación de Geógrafos Españoles celebrado en 2015 en Zaragoza.
}

Copyright: (C) 2017 CSIC. Este es un artículo de acceso abierto distribuido bajo los términos de una licencia de uso y distribución Creative Commons Attribution (CC-by) España 3.0. 
partir de los carbones depositados en el suelo, destacando el hallazgo de carbón de Abies pinsapo, especie de abeto amenazada ausente actualmente en la localidad.

PALABRAS CLAVE: Rocas ultramáficas; peridotita; endorreismo; ecosistema serpentínico; Abies pinsapo.

\begin{abstract}
Is presented the recent discovery and characterization of a endorheic basin at the summit of the Sierra Palmitera, an abrupt foothill of the peridotite massif of Sierra Bermeja (SW of Spain) that reaches 1,473 meters above sea level. Given the nature of this littoral ultramafic mountain, this basin is considered a geomorphological exceptionality for the whole of the known peridotite outcrops. Fieldwork and interpretation of photographs, main methodological procedures of the research, and the use of GIS have allowed a first geographical reconnaissance and the mapping of the main physical features to detail scale (1:5.000). The obtained results are: (1) a topographic map (equidistance of 5 meters) as basis of the thematic mapping; (2) the identification, characterization and mapping of the major geomorphological and edaphic units to the mentioned scale; (3) the characterization of the vegetation and flora of the basin through the phytosociological analysis, and the development of a vegetation map to scale detail. These results provide knowledge about the origin of the basin, its operation and its ecological role. As outstanding feature, the accumulation of sediment at the bottom of the basin allows the paleo-ecological study of vegetation from the charcoals deposited on the soil, highlighting the finding of charcoal of Abies pinsapo, species of spruce threatened currently absent in the location.
\end{abstract}

KEY WORDS: Ultramafic rocks; peridotite; endorreism; serpentine ecosystem; Abies pinsapo.

\section{Introducción}

El endorreismo constituye una excepcionalidad geomorfológica para el conjunto de los afloramientos ultramáficos conocidos, dada la naturaleza masiva e impermeable de este tipo de sustrato; las depresiones ultramáficas pueden tener su origen en el glaciarismo de alta montaña, caso de Klamath Mountains (Estados Unidos; Alexander et al., 2007), Red Mountain (Nueva Zelanda; Lee, 1992) o Monte Sandiras (Turquía; Sarikaya et al., 2008). No obstante, se han detectado formas de disolución (karst) en antiguas superficies de rocas ultramáficas tanto en los trópicos (Cuba, Indonesia, Nueva Caledonia), como en las zonas templadas (Grecia), debido a la solubilidad de algunos minerales ricos en magnesio bajo condiciones cálidas y elevadas concentraciones de $\mathrm{CO}_{2}$ (Wirthmann, 1970, 2000; Loffler, 1978; Riel \& Papadopoulou-Vrynioti, 2001; Pacheco et al., 2003; Hope, 2015).

En España no existen antecedentes en la literatura científica (Dantín Cereceda, 1940; Arias García, 2015), para contextualizar el reciente hallazgo de una cuenca endorreica en la línea de cumbres de la Sierra Palmitera. Esta sierra litoral es una estribación peridotítica de Sierra Bermeja y se caracteriza por tener la más agreste arista cimera. Tanto su accidentada orografía, como la escasez de infraestructuras viarias, explican la ausencia de exploraciones científicas previas y las deficiencias de la cartografía topográfica oficial (Figura 1).

El objetivo principal de este trabajo consiste en la subsanación de las deficiencias existentes en el conocimiento geográfico general del ámbito de estudio, tanto del medio natural como de su posible humanización. Para su consecución se plantean los siguientes objetivos secundarios: (1) incrementar el conocimiento de la realidad topográfica y geomorfoédafica de la cuenca, (2) incrementar el conocimiento de la composición y distribución de la vegetación actual y pasada, y (3) determinar si se han llevado a cabo usos antrópicos.
De acuerdo con los objetivos planteados, y frente a la ausencia de datos previos, en este trabajo se presenta la identificación de la cuenca y se realiza una cartografía y caracterización geográfica preliminar de sus principales rasgos geográficos. El interés de los resultados podría resumirse, en apretada síntesis, en tres aspectos: (1) el hallazgo de un nuevo accidente geográfico en la península ibérica; (2) la excepcionalidad geomorfológica; (3) la singularidad de los ecosistemas serpentínicos identificados así como de su evolución paleoecológica.

A tenor de los resultados, son tres las líneas de investigación a desarrollar en el futuro: el estudio de la génesis geomorfo-edáfica, el inventariado de la flora y la datación radiocarbónica de los restos de carbón vegetal.

\section{Metodología}

\subsection{Métodos}

Se ha realizado un análisis integrado del medio físico que contempla el estudio preliminar del relieve, los suelos, la vegetación y los usos antrópicos. El análisis de cada componente del medio ha requerido de un procedimiento metodológico particular, si bien, en general, el trabajo de campo y la interpretación de fotografías aéreas han sido los principales procedimientos metodológicos de la investigación, así como el uso de un sistema de información geográfica (ArcGis 10.1) para la elaboración de la cartografía topográfica y temática.

El estudio del relieve parte de la identificación visual sobre fotografía aérea de una "supuesta cuenca endorreica" en septiembre de 2012. La realización de una primera incursión a la zona (26 de abril de 2013) permitió corroborar dicha suposición. Dado que la cartografía topográfica existente no refleja la presencia de una depresión, en primer lugar se procedió a la delimitación de la misma y a su cartografiado detallado (base topográfica) utilizando 

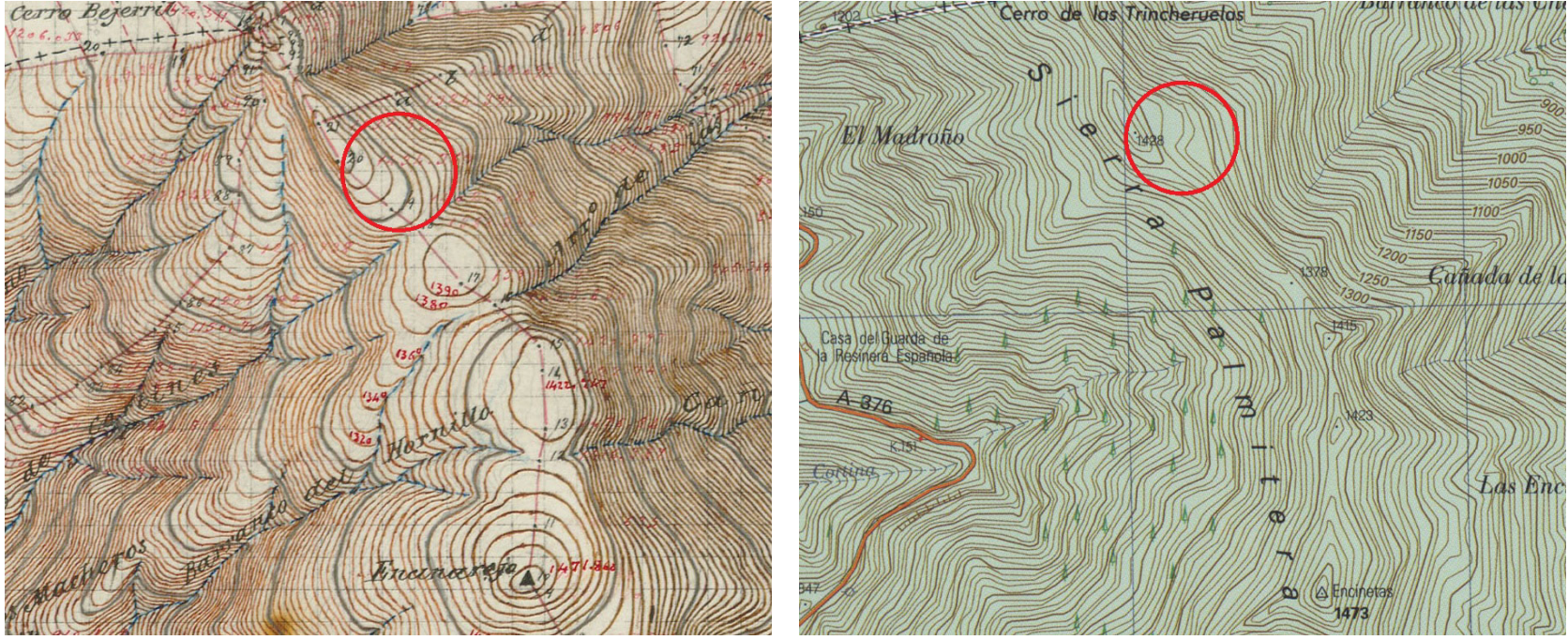

Figura 1: Detalle de la topografía antigua y actual de la cumbre de Sierra Palmitera donde no se representa la cuenca endorreica. Fuente: Instituto Geográfico Nacional (IGN). Izquierda: Trabajos Topográficos de Benahavís, 1897; Derecha: MTN25 Hoja 1065 , 2013.

Figure 1: Detail of the antique and current topography of the summit of Sierra Palmitera where it was not represented the endorheic basin. Source: National Geographic Institute of Spain (IGN). Left: Topographical Works of Benahavis, 1897; Right: National Topographic Map of Spain (MTN25) Sheet 1065, 2013.

como fotografía de referencia la imagen del PNOA de la hoja 1065 con sistema de proyección ETRS89 y huso 30 (fecha de vuelo 07-2013), y la capa vectorial altimétrica de $2 \mathrm{~m}$ de equidistancia obtenida a partir del modelo digital del terreno del IGN. Esta cartografía topográfica presenta una salida gráfica de isolíneas altimétricas con equidistancia $5 \mathrm{~m}$ extraídas del modelo digital del terreno de España con paso de malla de $5 \mathrm{~m}$. En segundo lugar, se procedió al análisis geomorfológico a partir de la fotointerpretación. Se han identificado, caracterizado y cartografiado a escala 1: 5000 las principales geoformas que, junto a las unidades de suelo, conforman el denominado mapa geomorfoedáfico. La información geológica de base procede de la bibliografía existente, en especial de la correspondiente hoja del MAGNA, completada y matizada mediante fotointerpretación y trabajo de campo. El trabajo de campo ha permitido la observación directa de la composición litológica, estructura y disposición de los elementos analizados a nivel superficial y subsuperficial, este último a través de un sondeo de $1 \times 1$ metro realizado para el posterior análisis pedoantracológico.

El análisis edáfico ha combinado trabajos de campo y gabinete a partir de dos tipos de sondeos: por un lado, un sondeo superficial en cinco puntos correspondientes con distintas unidades geomorfológicas identificadas previamente. Para ello, se han tomado muestras de 500 gr de suelo a $10 \mathrm{~cm}$ de profundidad, habiéndose medido en el Laboratorio de Edafología de la Universidad de Granada el $\mathrm{pH}$ (pH-metro), la conductividad en $\mu \mathrm{S}$ (conductímetro) y la carga de metales pesados en ppm (espectrómetro de rayos X). Por otro lado, un sondeo en profundidad (sondeo pedoantracológico anteriormente referido) ha permitido obtener información sobre la antracomasa y las especies asociadas al carbón vegetal correspondiente. Dicho sondeo se ha realizado a pico y pala en el fondo de la cubeta, alcanzando $70 \mathrm{~cm}$ de profundidad; se han identificado 5 niveles de muestreo delimitados a partir de la descripción de los horizontes edáficos. La separación e identificación del carbón se ha realizado tomando como base el procedimiento descrito por Carcaillet \& Thinon (1996) y Talon et al. (1998). Las mallas de tamizado y los consecuentes tamaños de los carbones han sido 4, 2 y $1 \mathrm{~mm}$. Se ha utilizado un microscopio episcópico Olympus BX 51 (50x, 100x, 200x y 500x) y una lupa trinocular C-LEDS. Los taxones fueron determinados con ayuda de los atlas de anatomía de maderas y carbones (Schweingruber, 1990a, 1990b; Vernet et al., 2001) y de la antracoteca propia del Laboratorio de Geografía Física de la Universidad de Granada realizada a partir de la carbonización de muestras de maderas locales.

La vegetación de la cuenca endorreica se ha estudiado a partir del método florístico-ecológico de delimitación de comunidades vegetales que tiene su fundamento en la Fitosociología clásica de la Escuela Sigmatista de ZurichMontpellier (ver Braun-Blanquet, J., 1979 y Rivas-Martínez, S., 1987). Este planteamiento ha supuesto el reconocimiento in situ a escala 1:1 de la totalidad del área de estudio con el objeto de identificar de manera específica las distintas comunidades integrantes del dosel vegetal y las especies integrantes de éstas, lo que ha permitido alcanzar un nivel de conocimiento suficiente para la caracterización vegetal del área de estudio. Como fuentes botánicas específicas de referencia se han utilizado las obras de Brooks et al. (1995), Cabezudo et al. (1998), Asensi et al. (2004), Pérez-Latorre et al. (2013), Gómez-Zotano (2014b) y Gómez Zotano et al. (2015b), a las que cabe 
añadir aquellas otras de carácter general de Castroviejo (2010) y Blanca et al. (2011). Los datos corológicos y fitosociológicos que se han incorporado provienen de Cabezudo et al. (1998), Pérez Latorre et al. (1998), Valle (2003) y Rivas-Martínez (2007, 2011). Este método ha permitido, asimismo, la georreferenciación mediante SIG de las principales formaciones vegetales que desde el punto de vista fisionómico identifican el paisaje vegetal a escala local, conformando el mapa de unidades de vegetación a escala 1:5000.

Para el estudio de los usos antrópicos se ha procedido, en primer lugar, al análisis y valoración de la información previa de origen histórico o arqueológico -recogida en Gómez Zotano (2004a), tanto de tipo cartográfico como bibliográfico. En segundo lugar, se ha realizado una prospección intensiva consistente en la inspección directa y exhaustiva de la superficie del terreno. Esta ha sido realizada por dos observadores separados a intervalos regulares de 10 metros y utilizando cuadrículas artificiales de $10 \times 10$ metros, hasta cubrir la totalidad de la cuenca y su entorno inmediato.

\subsection{Contexto territorial del ámbito de estudio}

El ámbito de estudio se sitúa al Sur de España $\left(36^{\circ} 35^{\prime} 53^{\prime}\right.$ ' N, 503'21' $\left.\mathrm{W}\right)$, en la línea de cumbres de la Sierra Palmitera, una montaña media vigorosa que alcanza 1473 m.s.n.m frente a la costa mediterránea. De litología peridotítica, forma parte del Manto Alpujárride de Los Reales que conforma el macizo ultramáfico de Sierra Bermeja, en la Serranía de Ronda, Cordillera Bética (Figura 2).

De acuerdo con Gómez-Zotano et al. (2015a), se enmarca en el dominio climático de media montaña identificado para el territorio de Andalucía, concretamente en la tipología "Clima mediterráneo semi-oceánico subhúmedo-húmedo de la Serranía de Ronda Oriental”. A pesar de su posición resguardada por la Serranía de Ronda, su altitud condiciona su pertenencia a la variante húmeda (precipitaciones anuales en torno a 1.000-1.300 mm), con temperaturas medias anuales que pueden situarse entre los $13-15^{\circ} \mathrm{C}$. Además, conviene advertir la proximidad del estrecho de Gibraltar, cuyo peculiar régimen de vientos trasciende hasta alcanzar decisivamente las sierras litorales del entorno. En el ámbito analizado, los regímenes de levante permiten la formación de nubosidad baja de retención y nieblas en las crestas, predominantes en verano en la zona del estrecho de Gibraltar (Dorman et al., 1995; Ibarra-Benlloch, 1989). Por ello, conviene resaltar la importancia de la criptoprecipitación (Valladares, 2009), especialmente en verano, y como entrada hídrica para la vegetación (López, coord., 2013).

A nivel biogeográfico, el ámbito de estudio pertenece al distrito Bermejense del sector Rondeño de la provincia corológica Bética. Su vegetación se caracteriza por la existencia de dos grandes dominios forestales, correspondientes a los pinares edafoxerófilos de Pinus pinaster, extendidos por buena parte del macizo, y a los abetales climatófilos de Abies pinsapo, limitados a determinadas cumbres (Los Reales, Abanto, Plaza de Armas y Corona). Según Rivas-Martínez (2011) estos bosques identifican, respectivamente, las series de vegetación exclusivamente bermejenses Querco cocciferae-Pinetum acutisquamae $S$. y Bunio macucae-Abietetum pinsapo $S$. Si bien estas coníferas circunmediterráneas constituyen las especies dominantes de las formaciones arbóreas que se desarrollan sobre sustratos ultramáficos, no son las únicas especies arbóreas que aparecen en Sierra Bermeja; la presencia variable de Quercus ha suscitado una enquistada controversia a la hora de determinar la vegetación climácica sobre este tipo de sustrato. Por otra parte, se ha reabierto el debate sobre la distribución de los pinsapares serpentinícolas en las cumbres de Sierra Bermeja, dada la dramática regresión sufrida en los últimos años por estos taxones relictos (Gómez-Zotano, 2004b).
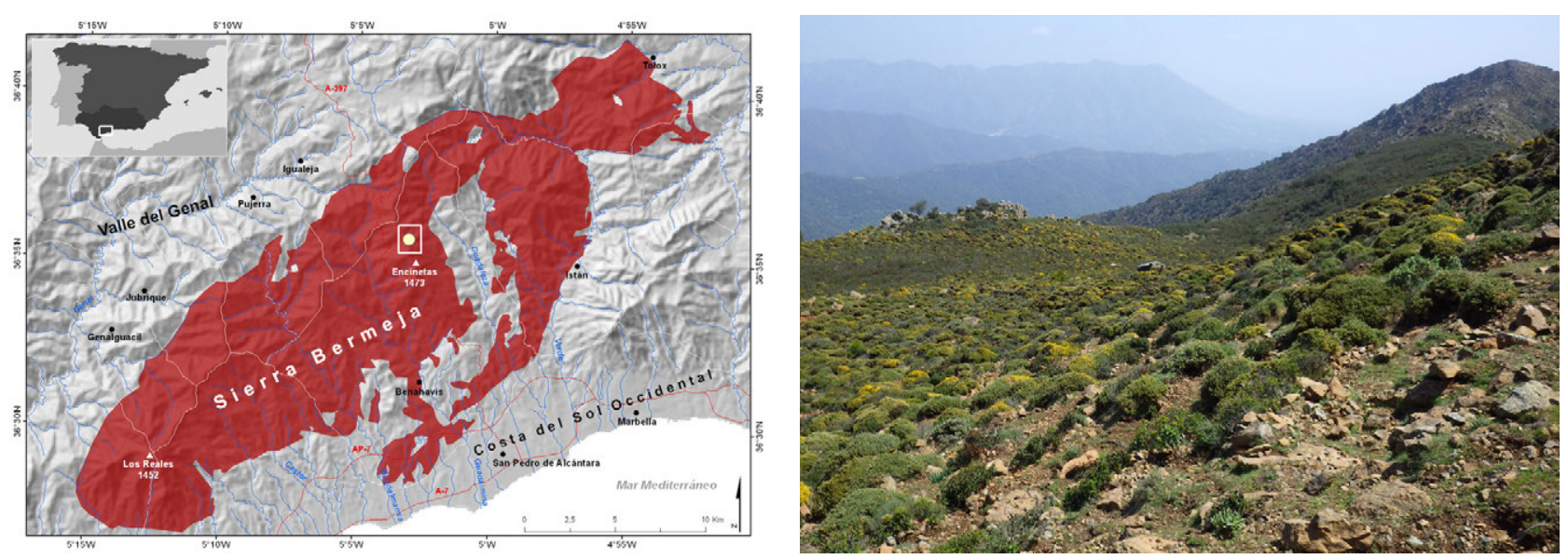

Figura 2: Mapa de situación (afloramiento ultramáfico en color bermejo) y aspecto general de la cuenca desde el cordón superior. Fuente cartográfica: Elaboración propia a partir de Rediam. Fotografía: José Gómez Zotano.

Figure 2: Location map (ultramafic outcrop in vermillion colour) and general aspect of the basin from the upper cord. Cartographic source: Based on Rediam. Photograph: José Gómez Zotano. 
La flora destaca por la presencia de numerosos taxones exclusivos de este macizo, que acusan fenómenos de serpentinomorfosis, y que están especialmente adaptados a los altos contenidos en metales pesados de los suelos serpentiníticos (Gómez-Zotano et al., 2014). Además, la toxicidad de estos suelos provoca la exclusión de buena parte de las especies de las formaciones mediterráneas circundantes, incluso de aquellas exóticas y/o invasoras (Rivas-Goday, 1969; Cabezudo et al., 1998; Asensi et al., 2004).

Las limitaciones inherentes a dicho subsistema natural, como pendientes escarpadas, toxicidad y alta pedregosidad o rocosidad del suelo, han limitado los aprovechamientos antrópicos a la explotación maderera del pino resinero, especialmente durante los siglos XIX y XX, y a la ganadería extensiva de caprino y ovino, vigente en la actualidad. Cabe considerar, además, la importancia que tienen los incendios forestales en la cubierta vegetal actual de Sierra Bermeja. Los episodios catastróficos de fuego, que en su mayor parte son de origen antrópico, presentan una marcada incidencia y una creciente proliferación desde 1960 (Gómez-Zotano, 2004a; Araque Jiménez, 2013), lo que ha provocado que una parte sustancial del macizo esté desarbolada, habiendo sido sustituidas las etapas climácicas arbóreas por facies seriales. La Sierra Palmitera fue plenamente afectada por grandes incendios en 1975 y 1991.

En relación con el sistema de protección ambiental, la Sierra Palmitera ha sido desigualmente reconocida y suma varias iniciativas que, en el contexto de Sierra Bermeja, le afectan en su totalidad: ZEC "Sierras Bermeja y Real" (COD ES6170010) y Reserva de la Biosfera Intercontinental del Mediterráneo Andalucía (España)-Marruecos. A pesar de ello, ha sido catalogada en su parte basal como Suelo Urbanizable en el planeamiento municipal de Benahavís, integrándose en la urbanización más exclusiva de Europa: "La Zagaleta" (Gómez-Zotano, 2004a; Gómez-Zotano et al., 2015a). Desde el año 2007 diferentes entidades públicas y colectivos sociales han propuesto la declaración del conjunto de Sierra Bermeja como Parque Nacional, la máxima apuesta de futuro de una Red compuesta por espacios naturales en buen estado de conservación que incluyen grandes ecosistemas representativos del Estado español, en este caso los ecosistemas serpentínicos (Garrido Marín et al., 2016).

\section{Resultados y discusión}

\subsection{Caracterización topográfica}

La delimitación del ámbito de estudio conforma una pequeña cuenca endorreica de 30 ha. de superficie y forma ovalada (Figura 3). Presenta una orientación NW-SE y un gradiente altitudinal de 68 metros, alcanzando 1.432 metros en la parte más alta y 1.364 metros en su fondo. Las pendientes oscilan entre llana y moderadamente escarpada a escarpada.

\subsection{Caracterización geomorfológica}

En primer lugar destacan las consecuencias morfológicas de carácter litológico. La cuenca se divide en dos unidades litológicas claramente diferenciadas: peridotitas (lherzolitas con plagioclasa y harzburgitas parcialmente serpentinizadas) y leucogranitos. Como puede observarse en el mapa geomorfo-edáfico (Figura 4), el relieve del afloramiento peridotítico se caracteriza por la presencia de diversas geoformas: las lherzolitas procuran unas laderas pedregosas y erosionadas, mientras que las harzburgitas favorecen el desarrollo de crestones dentellados y caos de grandes bloques heterométricos de hasta 8-10 metros de eje mayor. Coincidiendo con la presencia de una falla que atraviesa la cuenca en sentido NW-SE, las harzburgitas están más serpentinizadas, siendo frecuente la aparición de crisotilos (asbestos) alineados en torno al eje de falla, que es resuelto en la divisoria de aguas con la formación de un collado. Las diferencias geomorfológicas entre peridotitas y serpentinas coinciden con las detectadas por Alexander \& DuShey (2011). Los frecuentes afloramientos líticos presentan un abundante diaclasado, característico de estas rocas ultramáficas, lo que explica, junto con la red de fallas, la fuerte fracturación de la roca y los grandes coluviones desarrollados al borde de la cuenca. La costra rojiza de serpentina -generada por la peridotita alterada por los agentes atmosféricos- está cargada de óxido de hierro y recubre el verde original de la roca de forma continuada por todo el afloramiento. Esta serpentinización atmosférica afecta también al micromodelado de la roca (microkarst serpentínico), que queda erizada por los cristales angulares y brillantes de piroxenos, más resistentes frente a la erosión.

Un dique granitoide o intrusión filoniana ácida de composición cuarzo-feldespática (leucogranitos) ocupa el $33,2 \%$ del ámbito de estudio y corta oblicuamente la foliación y el bandeado de las peridotitas en sentido NWSE, al igual que el resto de filones verticales de rocas ácidas de Sierra Bermeja concordantes con las grandes roturas del afloramiento ultramáfico (Acosta Vigil, 1997). El roquedo aflora en superficie y se caracteriza por su dureza, el color blanco puro y su aspecto externo de granito de grano grueso a fino.

Además de las consecuencias morfológicas derivadas de una litología particular, los principales rasgos fisiográficos de la cuenca, así como su endorreísmo excepcional - dada la impermeabilidad constatada de las rocas ultramáficas (Sener et al., 2005)-, se derivan de un hecho de raigambre estructural; una red de fallas lístricas que, en sentido NW-SE, atraviesa la cuenca y genera cuatro escalones y rellanos que se van sucediendo de norte a sur en sentido descendente. El último de ellos, por intersección del sistema de fallas, y de acuerdo con las observaciones realizadas en la presente investigación, conforma una depresión cerrada por el dique intruido en las peridotitas, que obstruye su avenamiento a través de una serie de coluviones. En el fondo de la depresión se ha generado un pequeño rellano de acumulación de arcillas de $1.100 \mathrm{~m}^{2} \mathrm{y}$ fondo plano. Pese a la inexistencia de sumidero, la super- 


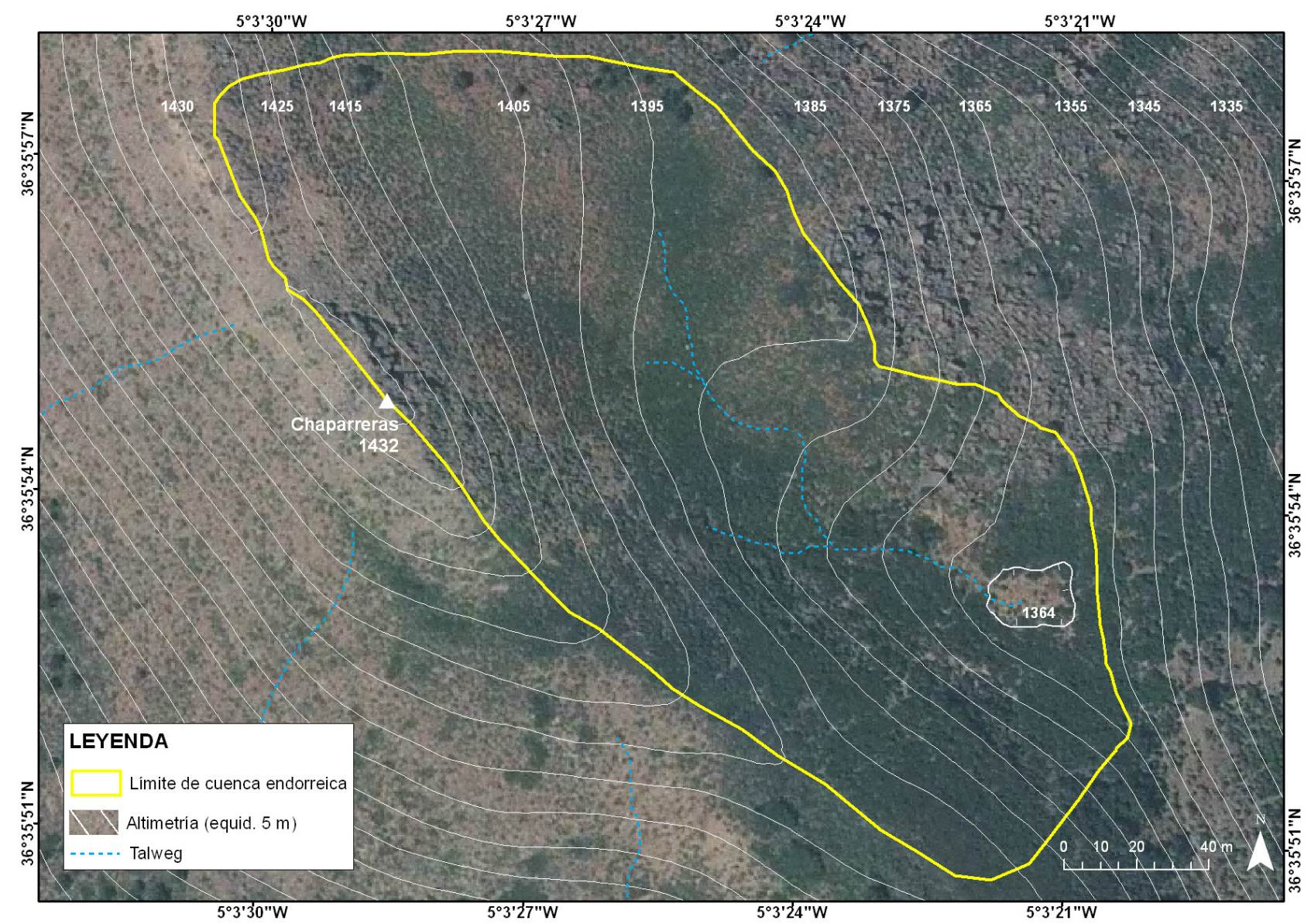

Figura 3: Mapa topográfico del ámbito de estudio. Fuente: Elaboración propia a partir de PNOA e IGN.

Figure 3: Topographical map of the study area. Source: Based on PNOA and IGN.

ficie no presenta indicios de encharcamiento (cuarteamiento u horizonte gris del suelo, vegetación higrófila), lo que refuerza la hipótesis de un lecho de origen coluvial que facilita la infiltración del agua.

El análisis superficial de la estructura y morfología del depósito de cierre de la cuenca parece descartar su origen glaciar (morrena terminal); la homogeneidad litológica (leucogranitos) y ausencia de peridotitas, a pesar de los afloramientos aguas arriba, son indicios que apuntan al escaso transporte del depósito. Similares resultados se obtienen al observar la morfología de los clastos en profundidad, con aristas vivas y sin ninguna evidencia de desgaste.

Respecto al posible modelado periglaciar de la cuenca endorreica -como del resto de las cumbres de la Sierra Palmitera-, Gómez Ortiz et al. (1994) señalan que en cercanos macizos calizos litorales se han encontrado evidencias de periglaciarismo a unos 800-1.000 metros de altitud: (1) manifestaciones de kartstogénesis periglacial a partir de $1.100 \mathrm{~m}$ y depósitos de grèzes litées desde unos $900 \mathrm{~m}$ en Sierra Blanca (1.270 m); y brechas, canchales y éboulis desde unos 800-900 m en Sierra Blanca y Sierra de Mijas $(1.150 \mathrm{~m})$. El mismo autor señala que se han encontrado morfologías de nivación más al interior y en sectores con similar precipitación, a partir de unos 1.500 m, como es el caso de la Sierra del Endrinal, en el cercano macizo de Grazalema. Por tanto, se puede considerar que durante las glaciaciones del Cuaternario los ciclos hielodeshielo y formación de clastos han participado en el modelado de determinadas zonas cacuminales de la Sierra Palmitera, si bien no es posible establecer a priori una relación sólida entre dicha dinámica y determinados aspectos morfológicos de la cuenca.

Tampoco se puede descartar una relación con los procesos de karstificación que afectaron a otras áreas ultramáficas con clima tropical-subtropical durante el Mioceno Medio (Riel y Papadopoulou-Vrynioti, 2001).

\subsection{Caracterización pedoantracológica.}

La poca potencia de los suelos conlleva el dominio de las tipologías leptosólicas frente a los regosoles, que reducen su existencia a la zona coluvial del fondo de la cuenca (Figura 4).

El primer grupo de suelos tiene una amplia implantación en las laderas de la cuenca y se desarrolla sobre toda la gama litológica descrita anteriormente. Los procesos erosivos externos, favorecidos por un régimen de precipi- 


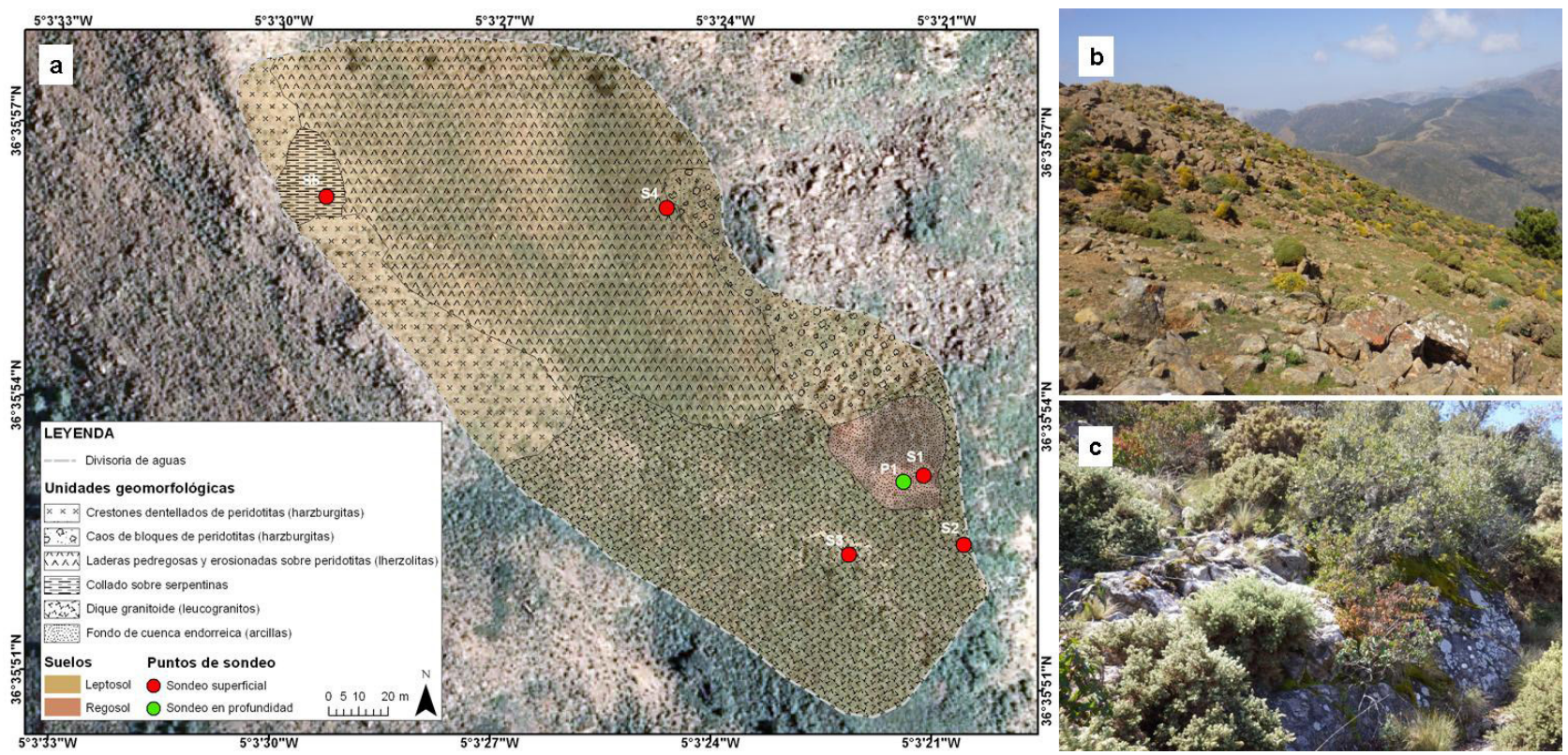

Figura 4: a) Mapa geomorfo-edáfico; b) Serpentinas y crestería de harzburgitas -en primer plano-, y laderas de peridotitas en el borde norte de la cuenca; c) Detalle del dique granitoide. Fuente: Elaboración propia a partir de PNOA e IGN. Fotografías: José Gómez Zotano.

Figure 4: a) Geomorphological and edaphic map; b) Serpentines and harzburgites on the crest-in the foreground-, and hillsides of peridotite in the northern border of the basin; c) Detail of the granitoid dike. Source: Based on PNOA and IGN. Photographs: José Gómez Zotano.

taciones irregulares $-\mathrm{y}$ en ocasiones torrenciales- material consolidado y fuertes pendientes, provocan el constante rejuvenecimiento del suelo pese a la densa vegetación. Se han identificado tres tipologías de Leptosoles: Leptosoles líticos, eútricos y móllicos. Todos ellos tienen en común la ausencia de carbonatos, pedregosidad y discontinuidades laterales causadas por los numerosos afloramientos. Los Leptosoles líticos no suelen superar los $10 \mathrm{~cm}$ y aparecen en las superficies más afectadas por la erosión. En el resto de las posiciones aparecen Leptosoles eútricos cuando llegan a los $30 \mathrm{~cm}$. En las zonas más resguardadas y de mayor densidad vegetal (caso del encinar sobre leucogranitos), pueden desarrollarse Leptosoles con epipedón móllico inferior a $30 \mathrm{~cm}$.

Los suelos evolucionados a partir de peridotitas con distinta composición mineralógica son siempre ricos en ferromagnesianos, responsables del fuerte y característico color rojo que presentan (el proceso de fersialitización da lugar a arcillas de neoformación a partir del olivino y los demás minerales accidentales). Destaca la abundancia de afloramientos rocosos de aspecto característico (microcarst serpentínico). Sobre las serpentinas de la divisoria de aguas, dada su posición topográfica y la escasa o nula cubierta vegetal, los suelos quedan expuestos a una intensa erosión hídrica y eólica, lo que explica su escasa potencia y la ausencia de horizontes móllicos, de ahí que no se hayan podido observar suelos con este epipedón.

Los Regosoles, por su parte, aparecen en el fondo de la cuenca sobre material no consolidado, coluvial, con más del $20 \%$ de tierra fina dentro de los $50 \mathrm{~cm}$ superficia- les. El perfil levantado muestra como los Regosoles evolucionan a partir de una formación de cantos heterométricos de granulitas (6-60 cm de eje mayor) embutidos en una matriz roja de naturaleza arcillosa. Presentan un epipedón ócrico en el que no se distinguen horizontes de diagnóstico. El pH ligeramente por debajo de 6 categoriza a este suelo como dístrico (FAO, 2014) (Figura 4).

Se han realizado cinco sondeos edáficos superficiales en distintos puntos de la cuenca (S1-5) con el fin de caracterizar los parámetros $\mathrm{pH}$, conductividad y metales pesados, así como un muestreo en profundidad para analizar la presencia de carbón en el suelo. Los datos obtenidos de los sondeos superficiales (Tabla 1) muestran unos niveles de $\mathrm{pH}$ crecientes desde el fondo de la cuenca hasta las posiciones más exteriores sobre peridotitas; los valores de $\mathrm{S} 1, \mathrm{~S} 2$ y S3 (fondo y dique granitoide) oscilan entre medianamente y ligeramente ácidos según la escala USDA, obteniendo valores característicos de suelos neutros-ligeramente básicos sobre peridotitas (S4) y serpentinas (S5). Cabe presuponer que las altas tasas de precipitación contribuyan al lavado de los suelos.

Los naturales procesos geoquímicos en la meteorización de las rocas peridotíticas conducen a la formación de suelos serpentiníticos. Como se puede observar en la Tabla 1, estos presentan factores edáficos muy singulares, en comparación con otros sustratos, incluyendo limitaciones excepcionales de nutrientes esenciales tales como $\mathrm{N}$, $\mathrm{P}, \mathrm{K}, \mathrm{y}$ un alto contenido en metales pesados tóxicos y/o sin función biológica conocida $(\mathrm{Cr}, \mathrm{Ni}, \mathrm{Co}, \mathrm{Cu})$. Este contenido en metales pesados, sensiblemente menor en 
los puntos S2 y S3 sobre el dique ácido, conlleva disfunciones en los organismos de los seres vivos y un carácter xerófilo de los suelos, con alta susceptibilidad a la erosión, tal y como han puesto de manifiesto Yusta et al. (1985), Aguilar et al. (1998), Rufo et al. (2005) y Mota et al. (2008). De acuerdo con Alexander \& DuShey (2011), debido a que generalmente se pierde $\mathrm{Ca}$ en el proceso de serpentinización, los materiales parentales de la serpentina tienen menos calcio que los materiales parentales de peridotita. Estos autores constatan, además, que los suelos peridotíticos son más rojizos que los serpentiníticos, dado el mayor contenido en Fe de las peridotitas, tal y como queda reflejado en la Tabla 1.

Por otra parte, los suelos derivados del dique ácido muestran tasas mucho más elevadas de $\mathrm{Sr}, \mathrm{Rb}, \mathrm{Zn}$, Ti y $\mathrm{K}$ que aquellos derivados de las rocas ultramáficas, relativamente empobrecidas en estos minerales. El suelo del fondo de la cuenca (S1) contiene una composición mineralógica más heterogénea debido a la influencia de las dos litologías, si bien destaca la alta tasa de $\mathrm{Cu}$ registrada.

Respecto al análisis pedoantracológico que se extrae del sondeo realizado en profundidad en el fondo de la cuenca (P1) (Figura 5) se puede destacar la existencia de elevadas tasas de carbón en suelo en todos los niveles identificados, lo que determinada niveles muy destacados de antracomasa (Figura 6). En particular, sobresale la importante acumulación de carbón en el nivel II (>74.000 $\mathrm{mg} / \mathrm{kg}$ ), lo que hay que relacionar con gran probabilidad con el incendio que arrasó la práctica totalidad de la Sierra Palmitera en 1975; los más que probables arrastres por erosión desde las laderas periféricas hasta el fondo de la cuenca en los primeros años tras el episodio de fuego contribuyeron previsiblemente a la acumulación de carbón, habiéndose formado por el mismo motivo desde entonces una capa de suelo de unos $15 \mathrm{~cm}$. De acuerdo con
Higuera (2005), las cuencas pequeñas responden al entorno inmediato, por lo que procuran un conocimiento más relevante y certero de la dinámica ecológica de la vegetación.

Los resultados preliminares de la identificación antracológica muestran un predominio de Quercus ssp.

Tabla 1: Resultados de los sondeos edáficos superficiales. Table 1: Results of the superficial edaphic soundings.

\begin{tabular}{|l|c|c|c|c|c|}
\hline VARIABLE & S1 & S2 & S3 & S4 & S5 \\
\hline $\mathrm{pH}$ & 5,96 & 6,08 & 6,07 & 6,51 & 7,28 \\
\hline $\begin{array}{l}\text { Conductividad } \\
(\mu \mathrm{S})\end{array}$ & 243 & 141 & 130 & 156 & 188 \\
\hline Metales pesados (ppm) \\
\hline $\mathrm{Sr}$ & 34,3 & 72,7 & 80,4 & 13,6 & 5,8 \\
\hline $\mathrm{Rb}$ & 48,6 & 35,8 & 44,7 & 18 & 7,3 \\
\hline $\mathrm{Pb}$ & 33,5 & 31,3 & 34,5 & 27,8 & 20,0 \\
\hline $\mathrm{Zn}$ & 66,8 & 54 & 41,8 & - & - \\
\hline $\mathrm{Cu}$ & 60,6 & 22,9 & 26,3 & 47,8 & - \\
\hline $\mathrm{Ni}$ & 1810 & 678,1 & 474,4 & 3964 & 2814 \\
\hline $\mathrm{Co}$ & 778,6 & - & - & 1171 & 621,9 \\
\hline $\mathrm{Fe}$ & 71.000 & 27.500 & 25.300 & 126.300 & 52.900 \\
\hline $\mathrm{Mn}$ & 1944 & 977,5 & 522 & 2761 & 1059 \\
\hline $\mathrm{Cr}$ & 3819 & 1145 & 792,1 & 7062 & 3432 \\
\hline $\mathrm{V}$ & - & 154,8 & 215,6 & 194,7 & - \\
\hline $\mathrm{Ti}$ & 4056 & 6659 & 7199 & 1901 & 545,5 \\
\hline $\mathrm{Ca}$ & 10.600 & 9424 & 8452 & 12.900 & 9312 \\
\hline $\mathrm{K}$ & 7144 & 6905 & 6882 & 3154 & 1929 \\
\hline
\end{tabular}
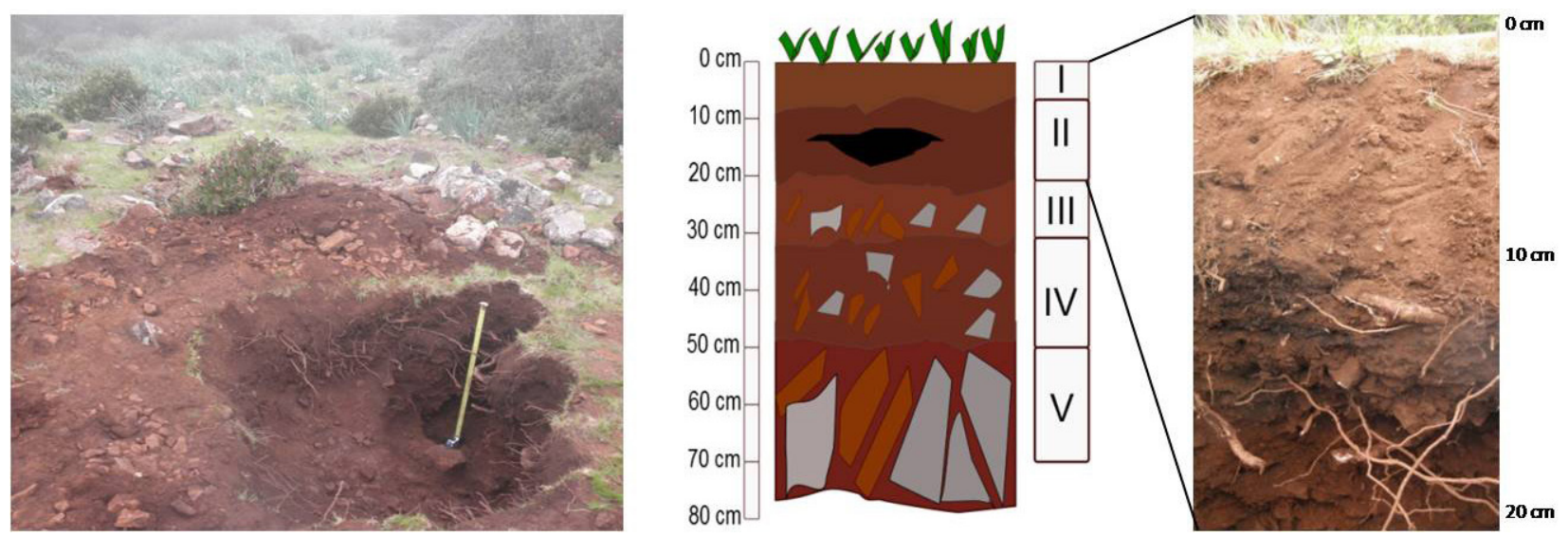

Figura 5: De izquierda a derecha, contexto del sondeo edáfico en profundidad (P1), características macromorfológicas del perfil y detalle de los dos primeros niveles de muestreo donde se puede apreciar la importante carga de carbón en N II. Fuente: Elaboración propia. Fotografías: José Gómez Zotano.

Figure 5: From left to right, context of the edaphic sounding in depth (P1), macro-morphological characteristics of soil profile and detail of the two firsts sampling levels where it is possible to observe the significant amount of charcoal in N II. Source: Own elaboration. Photographs: José Gómez Zotano. 


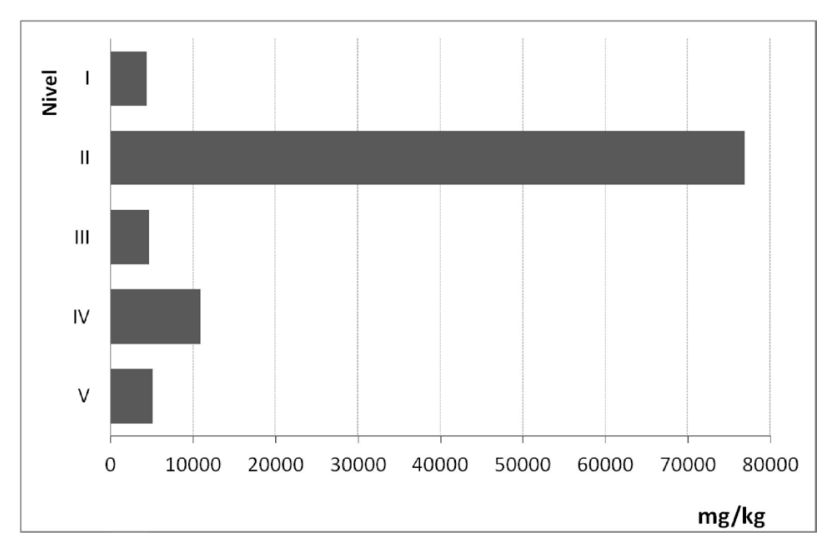

Figura 6: Antracomasa (mg carbón/kg suelo) por niveles de muestreo. Fuente: Elaboración propia.

Figure 6: Antracomass (mg charcoal/kg soil) by sampling levels. Source: Own elaboration.

(35-70\%) en cuatro de los cinco niveles identificados en P1 (I, II, III y V), lo que coincide con la vegetación actual presente en el ámbito de estudio. Como excepción, frente a una muy escasa o nula representación de coníferas en I, II, III y V (0-10\%), el cuarto nivel en profundidad presenta como vegetación preponderante a Pinus ssp. (50\%), quedando Quercus ssp. en una posición muy secundaria (10\%). Mayor trascendencia tiene, si cabe, la identificación en este mismo nivel de carbón de Abies ssp. (Abies pinsapo) (4\%), constatando la existencia pretérita de bosques de abetos en la cima de la Palmitera, si bien queda por determinar su antigüedad. Este hecho, sin duda, reaviva la controversia biogeográfica latifolias-coníferas sobre sustratos ultramáficos en clima mediterráneo (Gómez-Zotano, 2004b), y corrobora que los abetales de Abies pinsapo constituyen la vegetación forestal cacuminal en Sierra Bermeja. Este cinturón superior de bosque, por tanto, presentaría una superficie mayor en el pasado, y, tal y como demuestra la vegetación actual, estaría rodeado por una amplia franja de pinar de Pinus pinaster coincidente prácticamente en su totalidad con el resto del afloramiento ultramáfico. Por su parte, Quercus ssp. parece refugiarse en aquellos suelos menos tóxicos y excluyentes procedentes de la edafización de intrusiones filonianas dentro del conjunto de las peridotitas bermejenses.

Por último, cabe destacar la elevada tasa de carbones vitrificados y, por tanto, no identificables, que se ha encontrado en todo el perfil (20-55\%). Sin embargo, no es posible establecer en la actualidad, y de manera general, las causas exactas del proceso de vitrificación; a día de hoy existen numerosas controversias e interrogantes sin respuesta en torno a los factores que lo propician (Vaschalde et al., 2011). En concreto, se pensaba, tradicionalmente, que la vitrificación era resultado de la exposición a altas temperaturas o de la combustión de madera verde, pero se ha demostrado en laboratorio que la vitrificación del carbón no está relacionada con estos dos supuestos (McParland et al., 2010).

\subsection{Caracterización de la vegetación}

Dentro del singular contexto lito-edáfico y mesoclimático del área de estudio se han diferenciado e identificado cinco comunidades vegetales con composición florística y distribución bien definidas (Figura 7). En primer lugar, destaca la aparición de un bosquete relicto de Quercus rotundifolia en el contexto de Sierra Bermeja, de carácter cerrado y talla media, con ejemplares de porte achaparrado-arborescente, sobre el dique ácido. Se trata de una tesela de vegetación, a falta de un estudio florístico detallado, asimilable a los encinares béticos de Paeonio coriaceae-Quercetum rotundifoliae Rivas Martínez (1964) en su variante termófila y calcífuga. La mancha perfila un estrato prácticamente monoespecífico hacia su interior, en el que solo destacan algunos esciófilos como Pteridium aquilinum, Viola kitaibeliana y Hiacinthoides hispanica, taxón este último posible indicador ecológico de Abies pinsapo. Hacia el exterior se enriquece con una segunda comunidad que, en parte, representa su etapa de sotobosque. Se trata de una densa formación de Cistus ladanifer, cuya composición florística principal está constituida básicamente por Cistus populifolius y, en menor medida, por Cistus salvifolius, Phlomis lychnitis, Daphne gnidium, Quercus coccifera, Genista lanuginosa y Ulex baeticus. Su acotación sintaxonómica en esta localidad se puede asimilar, aunque con reservas, a los jarales de Calicotomo villosae-Genistetum hirsuti (Martínez-Parras et al., 1988), propios de Teucrio baetici-Quercetum suberis $S$.

Fuera de la influencia directa del dique granitoide aparecen dos comunidades de matorral que forman parte, habitualmente, de la sucesión vegetal teórica de los abetales bermejenses de Bunio macucae-Abietetum pinsapo $S$. Se trata de un piornal de Ulex baeticus y Genista lanuginosa, y de un jaral de Cistus populifolius, que integran la asociación Genisto lanuginosae-Cistetum populifolii (Asensi \& Díez Garretas, 1992), exclusiva de Sierra Bermeja, y que es representativa de la degradación de las etapas de prebosque de orla del pinsapar. El piornal se asienta sobre los suelos más serpentiníticos, es decir, en las posiciones más alejadas del dique ácido y de su influencia edáfica; en general presenta una cobertura vegetal medioalta, y está integrado básicamente por Genista hirsuta ssp. lanuginosa, Ulex baeticus, Cistus populifolius ssp. major, Cistus salvifolius, Thymus baeticus, Lithodora prostrata ssp. lusitanica, Phlomis lychnitis, Halimium atriplicifolium ssp. atriplicifolium, Erodium cicutarium, Prolongoa hispanica, Quercus coccifera, pies aislados de Pinus pinaster var. acustiquama y los endemismos serpentinófilos exclusivos de Sierra Bermeja Armería colorata y Alyssum serpillifolium ssp. malacitanum. El jaral, que como formación vegetal presenta un carácter mucho más difuso, parece conformar una banda de vegetación de transición entre el piornal y la formación de Cistus ladanifer, siendo común su desarrollo mixto con ambas. Esto favorece una mayor variabilidad florística, apareciendo, junto a Cistus populifolius, la mayor parte de los taxones integrantes del piornal. 

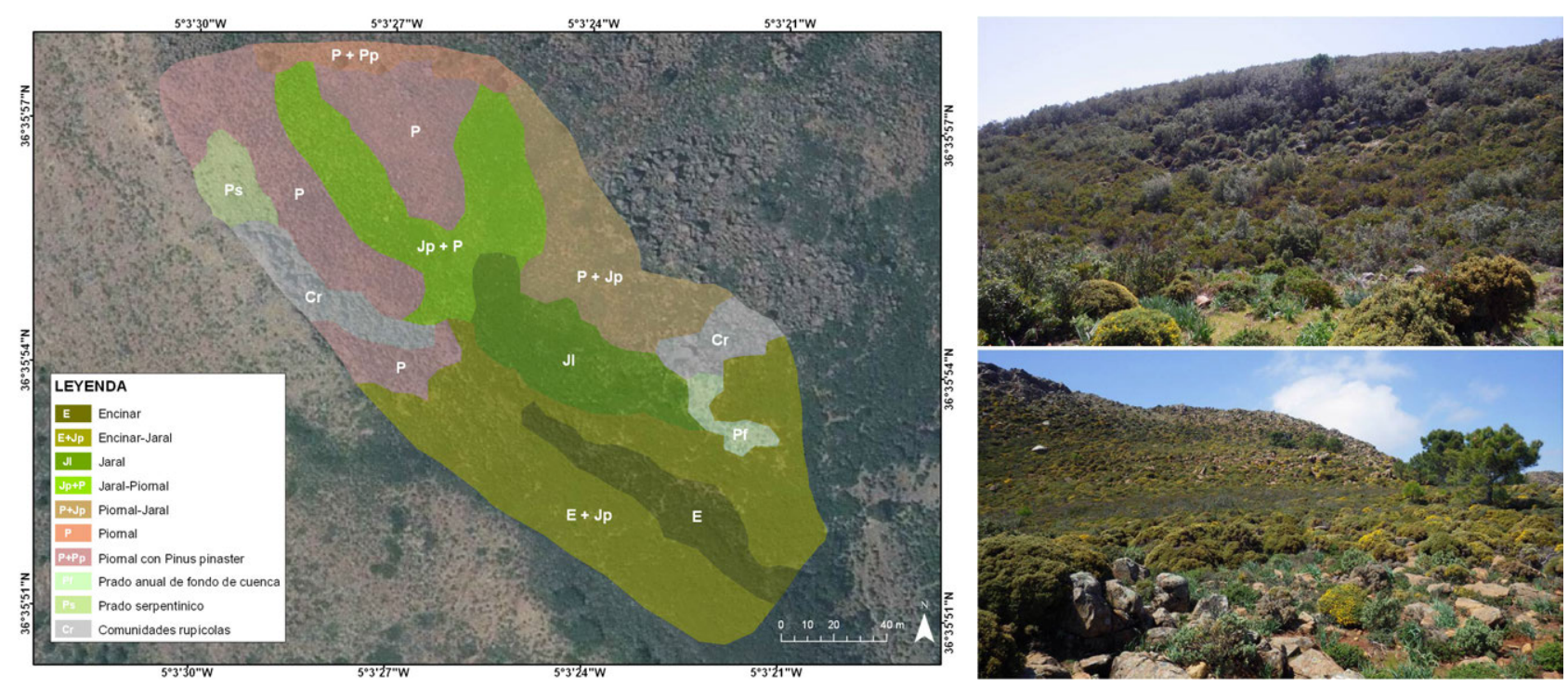

Figura 7: Mapa de unidades de vegetación. En la fotografía superior se puede apreciar la banda de encinar (E, E+Jp) restringida básicamente al dique granitoide. En la imagen inferior la comunidad de piornal $(\mathrm{P})$ con pies aislados de Pinus pinaster $(\mathrm{P}, \mathrm{P}+\mathrm{Jp}$,

$\mathrm{P}+\mathrm{Pp}$ ) sobre peridotitas en la mitad norte de la cuenca. Fuente: Elaboración propia. Fotografías: José Gómez Zotano.

Figure 7: Map of vegetation units. In the upper photograph it is possible to observe the fringe of holm oaks -Quercus rotundifolia-

$(E, E+J p)$ basically restricted to the granitoid dike. In the bottom image appears the community of spiny scrub $(P)$ with isolated specimens of Pinus pinaster $(P, P+J p, P+P p)$ over peridotites in the northern half of the basin. Source: Own elaboration. Photographs: José Gómez Zotano.

En el fondo de la cuenca, sobre los regosoles, aparecen las praderas de diente. Se trata de la quinta comunidad, en este caso de mayor espectro ecológico, identificable como Poo bulbosae-Astragaletum sesamei Rivas-Goday \& Ladero (1970). Este pequeño majadal está integrado por distintas especies de Poa, Trifolium, Festuca, etc., y se ve favorecido por la nitrificación edáfica debido a la fauna (Sus scrofa principalmente) y a la presencia ocasional de ganado doméstico, siendo frecuentes, por este motivo Asphodelus ssp. En los prados anuales que se desarrollan en el collado de serpentinas se puede encontrar Sesamoides canescens, Trifolium sp., Leucanthemum sp., Leucanthemum plantula, Leontodon longirostris, Erodium, Valeriana tuberosa o Alyssum serpyllifolium subsp. malacitanum. La última comunidad está compuesta por las formaciones rupícolas que colonizan los roquedos peridotíticos. Destaca la presencia de Ruscus aculeatus, Cystopteris fragilis, Asplenium trichomanes, Asplenium ceterach o Bromus tectorum.

Los análisis pedoantracológicos, contrastados con el estudio de la vegetación actual, despejan dudas sobre la enquistada controversia latifolias-coníferas en sustratos ultramáficos. Tal y como se ha evidenciado, el encinar muestra una clara relación con los suelos derivados del dique ácido. No obstante, la toponimia local hace alusión, reiteradamente, a la presencia de Quercus en el entorno inmediato de la cuenca analizada (Encinetas, Las Chaparreras, barranco de Las Chaparreras; Gómez-Zotano, 2004b). Además, aparecen ejemplares aislados de encina entre los bloques peridotíticos. Es posible que, con independencia de la toxicidad de los suelos serpentíniticos, esta especie encuentre su mejor refugio en la crestería de la Sierra Palmitera, donde se beneficia de un aporte hídri- co extra debido a la criptoprecipitación, y se mantiene a resguardo del diente del ganado y de los recurrentes incendios forestales.

A su vez, la presencia de matorral serial propio de los bosques serpentinófilos de Abies pinsapo en este particular nicho ecológico concuerda con la existencia pretérita de un abetal en determinadas ubicaciones topográficas de la Sierra Palmitera.

\subsection{Aproximación a las actividades y usos antrópicos}

La depresión denota una escasa presencia humana. En las fuentes cartográficas y bibliográficas analizadas, así como en el reconocimiento arqueológico superficial llevado a cabo, no se han detectado signos de actividad antrópica dada la ausencia de datos o restos cerámicos y elementos construidos. Estos resultados provisionales resultan controvertidos dada la existencia de una importante red de asentamientos en altura distribuida por las cumbres de Sierra Bermeja, incluida la Sierra Palmitera (a 1.372 m.s.n.m. se levanta el asentamiento altomedieval del Castillejo de los Negros, a 2,7 km de longitud al sur de la cuenca) (Navarro et al., 1996). Por otra parte, al sureste, en el valle del río Guadaiza y a una distancia de $2,5 \mathrm{~km}$, se encuentra el despoblado bajomedieval de Daidín. En cualquier caso, los usos y actividades antrópicos quedan reducidos a una testimonial ganadería extensiva ovina y caprina que, no obstante, ha podido alterar profundamente la vegetación (talas, incendios forestales provocados para ganar terrenos de pasto y seleccionar especies; GómezZotano, 2006). 


\section{Conclusiones}

Entre los resultados del trabajo destacan el hallazgo científico y la caracterización geográfica general de una depresión que por su naturaleza litológica resulta de gran interés en el contexto de los afloramientos ultramáficos de los medios templados. Es la primera cuenca endorreica conocida en línea de cresta en una montaña litoral mediterránea de naturaleza ultramáfica que se ha configurado por la obstrucción del avenamiento de las aguas debido a una intrusión filoniana que la cierra; se pone de manifiesto que la tectónica, como factor geológico endógeno, determina la aparición del fenómeno endorreico en Sierra Bermeja, guardando relación a su vez con la distribución por sectores de los tipos geomorfoedáficos establecidos, así como con diversos fenómenos y procesos geomorfológicos asociados: (1) orientaciones preferentes de la red de fallas en función de la tectónica local, (2) el tipo de sedimentación (fondo de arcillas procedentes del proceso de serpentinización de la roca peridotítica), (3) los datos morfométricos no muestran evidencias de glaciarismo, pero no se descarta la participación de factores geológicos exógenos (karstificación) o de periglaciarismo en la configuración actual del relieve.

Además, a pesar de sus reducidas dimensiones, la depresión presenta una compleja estructura y dinámica vegetal; se configura como enclave refugio para especies que actualmente tienen una escasa presencia en el conjunto de Sierra Bermeja, caso de Quercus rotundifolia. Asimismo, destaca la aparición de carbón de Abies ssp. en el fondo de la cuenca, lo que indica la existencia pretérita de Abies pinsapo en la cumbre de la Sierra Palmitera, localidad donde está ausente en la actualidad, de manera acorde a las comunidades y taxones bioindicadores del pinsapar que se han encontrado. Este hallazgo aporta, sin duda, un conocimiento fundamental para el estudio paleobotánico en el Sur de España de esta especie de abeto amenazada, y reaviva la controversia biogeográfica latifolias-coníferas sobre sustratos ultramáficos en clima mediterráneo.

En próximas investigaciones se atenderán aquellos aspectos que ayuden a comprender la génesis geomorfoedáfica, la fitogeografía y la paleoecología del ámbito de estudio.

La identificación y caracterización de este accidente geográfico, de gran interés para el conocimiento de Sierra Bermeja, suponen también una aportación a su extraordinaria geodiversidad y biodiversidad, valores naturales que serán implementados en la actual propuesta de Parque Nacional Sierra Bermeja.

\section{Agradecimientos}

Los resultados de esta investigación forman parte del Proyecto de I+D ULTRAFORESTS (CSO2013-47713-P) subvencionado por el Ministerio de Economía y Competitividad del Gobierno de España. Agradecemos la utilización de los laboratorios a los departamentos de Edafología, Química Inorgánica y Análisis Geográfico Regional y
Geografía Física de la Universidad de Granada, así como la colaboración de Geof Hope (The Australian National University), Fernando Gervilla Linares (Universidad de Granada), Andrés Pérez Latorre (Universidad de Málaga), Juan Antonio Marco Molina (Universidad de Alicante), Javier Martos Martín (Geonatura Sur S.L.) e Ildefonso Navarro Luengo (Ayuntamiento de Estepona).

\section{Referencias}

Acosta Vigil, A., 1997. Estudio de los fenómenos de fusión cortical y generación de granitoides asociados a las peridotitas de Ronda. Tesis Doctoral. Universidad de Granada, 305 pp.

Aguilar, J., Calvo, R., Fernández, E. \& Macías, F., 1998. Geoquímica de la alteración y edafogénesis de rocas serpentinizadas de la Sierra Bermeja (Málaga). Edafología, 5: 135-151.

Alexander, E. B., Coleman, R. G., Keeler-Wolf, T. \& Harrison, S. P., 2007. Serpentine Geoecology of Western North America. Oxford University Press, New York.

Alexander, E. B. \& DuShey, J., 2011. Topographic and soil differences from peridotite to serpentinite. Geomorphology, 135: 271-276. http://dx.doi.org/10.1016/j.geomorph.2011. 02.007 .

Araque Jiménez, E., 2013. Medio siglo de grandes incendios forestales en Andalucía (1961-2011). Méditerranée, 121: 4152. http://dx.doi.org/10.4000/mediterranee.6840.

Arias García, J., 2015. Identificación, caracterización y cualificación de los paisajes de las grandes cuencas endorreicas de Andalucía: ensayo metodológico para la implementación del Convenio Europeo del Paisaje en sistemas lacustre-palustres. Tesis Doctoral. Universidad de Granada, 571 pp. + 76 mapas.

Asensi, A., Díez-Garretas, B. \& de la Fuente, V., 2004. Vegetation of ultramafic rocks in the Iberian Peninsula. En: Boyd, R.S., Baker, A.J.M., Proctor J., Eds. Ultramafic Rocks: Their Soils, Vegetation, and Fauna. St. Albans, Herts (UK), Science Reviews: 137-143.

Blanca, G., Cabezudo, B., Cueto, M., Morales, C., \& Salazar, C., 2011. Flora Vascular de Andalucía Oriental (4 ${ }^{\mathrm{a}}$ ed.). Consejería de Medio Ambiente de la Junta de Andalucía, Sevilla.

Braun-Blanquet, J., 1979. Fitosociología. Bases para el estudio de las comunidades vegetales ( $3^{\mathrm{a}}$ ed.). Blume, Barcelona.

Brooks, R. R., Dunn, C. E., Edmonson, J., Targuisti, K., Asensi, A. \& Reeves, R. D., 1995. Phytosociological and biogeochemical observations on the serpentinite vegetation of the Betic Riffian ultramafic arc of Spain and Morocco. Ofioliti, 20 (2): 67-79.

Cabezudo, B., Pérez-Latorre, A., Navas, P., Gil, Y. \& Navas, D., 1998. Paraje Natural de los Reales de Sierra Bermeja. Cartografía y Evaluación de la flora y vegetación. Universidad de Málaga, Málaga.

Carcaillet, C. \& Thinon, M., 1996. Pedoanthracological contribution to the study of the evolution of the upper treeline in the Maurienne Valley (North French Alps): methodology and preliminary results. Review of Palaeobotany and Palynology, 91: 399-416. http://dx.doi.org/10.1016/00346667(95)00060-7.

Castroviejo, S., 2010. Flora Ibérica. Plantas Vasculares de la Península Ibérica e Islas Baleares. Real Jardín Botánico-Consejo Superior de Investigaciones Científicas, Madrid.

Dantín Cereceda, J., 1940. La aridez y el endorreismo en España. El endorreismo bético. Estudios Geográficos, 1: 75-117.

Dorman, C. E., Beardsley, R. C. \& Limeburner, R., 1995. Winds in the Strait of Gibraltar. Q. J. R. Meteorol. Soc., 121: 19031921. doi: 10.1002/qj.49712152807. 
FAO 2014. World reference base for soil resources. United Nations, Rome.

Garrido Marín, C., Gervilla Linares, F., Gómez Zotano, J., Hidalgo Triana, N., Martos Martín, J., Navarro Luengo, I., Pérez Latorre, A.V., Román Requena, F. \& Suárez Padilla, J., 2016. Memoria científico-técnica sobre el afloramiento ultramáfico de Sierra Bermeja (Málaga) como justificación para su declaración como Parque Nacional. Plataforma Sierra Bermeja Parque Nacional.

Gómez Ortiz, A., Díaz del Olmo, F. \& Simon Torres, M., 1994. Periglaciarismo en las Cordilleras Béticas. En: Gómez Ortiz, A., Simón Torres, M., Salvador Franch, F. (Eds.) Periglaciarismo en la Península Ibérica, Canarias y Baleares. Estudios significativos. SEG-Universidad de Granada, 165188, Granada.

Gómez-Zotano, J., 2004a. El papel de los espacios montañosos como traspaís del litoral mediterráneo andaluz: el caso de Sierra Bermeja (provincia de Málaga). Universidad de Granada, Granada.

Gómez-Zotano, J., 2004b. Controversia árboles latifolios-versus coníferas en Sierra Bermeja, una montaña ultramáfica del sur de España. En: Boyd, R. S., Baker, A. J. M., Proctor J. (Eds.) Ultramafic Rocks: Their Soils, Vegetation, and Fauna. St. Albans, Science Reviews, 151-156, Herts (UK).

Gómez-Zotano, J., 2006. Naturaleza y paisaje en la Costa del Sol Occidental. Centro de Ediciones de la Diputación de Málaga, Málaga.

Gómez-Zotano, J., Román-Requena, F., Hidalgo-Triana, N. \& Pérez-Latorre, A. V., 2014. Biodiversidad y valores de conservación de los ecosistemas serpentínicos en España: Sierra Bermeja (provincia de Málaga). Boletín de la Asociación de Geógrafos Españoles, 65: 187-206.

Gómez-Zotano, J., Alcántara-Manzanares, J., Olmedo-Cobo, J.A. \& Martínez-Ibarra, E., 2015a. La sistematización del clima Mediterráneo: Identificación, clasificación y caracterización climática de Andalucía (España). Revista Norte Grande, 61: 161-180. http://dx.doi.org/10.4067/S071834022015000200009 .

Gómez-Zotano, J., Román Requena, F. \& Thorne, J.H., 2015b. Attributes and roadblocks: a conservation assessment and policy review of the Sierra Bermeja, a Mediterranean serpentine landscape. Natural Areas Journal, 35(2): 328-343. http://dx.doi.org/10.3375/043.035.0215.

Higuera, P. E., 2005. Reconstructing fire regimes with charcoal from small-hollow sediments: a calibration with tree-ring records of fire. The Holocene, 15: 238-251. https://doi. org/10.1191/0959683605hl789rp.

Hope, G., 2015. Extended vegetation histories from ultramafic karst depressions. Australian Journal of Botany, 63: 222233. doi: 10.1071/BT14283.

Ibarra-Benlloch, P., 1989. La influencia de los vientos del estrecho de Gibraltar en la vegetación arbórea. Cuadernos de Geografia, 1: 61-84.

Lee W. G., 1992. New Zealand Ultramafics. In: The Ecology of Areas with Serpentinized Rocks. A World View (Eds B.A. Roberts, J. Proctor): 375-417pp., Springer. http://dx.doi. org/10.1007/978-94-011-3722-5_15.

Loffler, E., 1978. Karst features in igneous Rocks in Papua New Guinea. En: J.L. Davies, M.A.J. Williams (Eds.) Landform evolution in Australasia, 238-249 pp., Australian National University Press, Canberra.

López, J. (coord.) 2013. Los pinsapares en Andalucía (Abies pinsapo Boiss.): Conservación y sostenibilidad en el siglo $X X I$. Servicio de Publicaciones de la Universidad de Córdoba, Córdoba.

McParland, L.C., Collinson, M.E., Scott, A.C., Campbell, G. \& Veal, R., 2010. Is vitrification in charcoal a result of high temperature of burning? Journal of Archaeological
Science, 37: 2679-2687. http://dx.doi.org/10.1016/j. jas.2010.06.006.

Mota, J. F., Medina-Cazorla, J. M., Navarro, F. B., Pérez-García, F. J., Pérez-Latorre, A. V. \& Sánchez-Gómez, P., 2008. Dolomite flora of the Baetic Ranges glades (South Spain). Flora, 203: 359-375. http://dx.doi.org/10.1016/j.flora.2007.06.006.

Navarro Luengo, I. et al., 1996. Aproximación a la dinámica poblacional del litoral occidental malagueño durante la Antigüedad: de Roma al Islam. Actas del I Congreso de Historial Antigua de Málaga y su provincia: 189-203 pp., Málaga.

Pacheco, R. R., Fabregat, S. \& Días-Martínez, R., 2003. Karstification in ultramafic rocks of Cuba (Abstract). En: G. Fang, J. Guanghui, T. Danning (Eds.) World correlation of karst ecosystem. Publishing House of Guangxi Normal University. http://www.karst.edu.cn/karst/igcp/igcp448/2003.

Pérez-Latorre, A.V., Navas, P., Navas, D., Gil, Y. \& Cabezudo, B., 1998. Datos sobre la Flora y Vegetación de la Serranía de Ronda (Málaga, España). Acta Botanica Malacitana, 23: 149-191.

Pérez-Latorre, A. V., Hidalgo-Triana, N. \& Cabezudo, B., 2013. Composition, ecology and conservation of the south-Iberian serpentine flora in the context of the Mediterranean basin. Anales del Jardín Botánico de Madrid, 70 (1): 62-71. http:// dx.doi.org/10.3989/ajbm.2334.

Rield, H. \& Papadopoulou-Vrynioti, K., 2001. Comparative investigations on karst generations mainly in the Aegean Archipielago. Mitteilungen Naturwissenschaftlicher Verein für Steiermark, 131: 23-39.

Rivas-Goday, S., 1969. Flora serpentinícola española, nota primera (Edafismos endémicos del Reino de Granada). Anales Real Academia de Farmacia, 35: 297-304.

Rivas-Martínez, S., 1987. Memoria del mapa de vegetación de España. ICONA, Madrid.

Rivas-Martínez, S., 2007. Mapa de Series, Geoseries y Geopermaseries de Vegetación de España. Itinera Geobotanica, 17: $1-435$.

Rivas-Martínez, S., 2011. Memoria del Mapa de Vegetación Potencial de España. Itinera Geobotanica, 18: 5-800.

Rufo, L., Rodríguez, N. \& Fuente, V., 2005. Análisis comparado de metales en suelos y plantas de la Sierra Bermeja. En: Jiménez, R., Álvarez, A.M. (Eds.) Proceedings II Simposio Nacional de Control de la Degradación de Suelos. Universidad Autónoma de Madrid, 197-201 pp., Madrid.

Sarikaya, M. A., Zreda, M., Çiner, A. \& Zweck, C., 2008. Cold and wet Last Glacial Maximum on Mount Sandiras, SW Turkey, inferred from cosmogenic dating and glacier modeling. Quaternary Science Reviews, 27: 769-780. doi: 10.1016/j.quascirev.2008.01.002.

Schweingruber, F.H., 1990a. Anatomie of European woods. Paul Haupt, Bern.

Schweingruber, F. H., 1990b. Microscopic wood anatomy: structural variability of stems and twigs in recent and subfossil woods from Central Europe. Federal Institute for Forest, Snow and Landscape Research, Swiss.

Sener, E., Davraz, A. \& Ozcelik, M., 2005. An integration of GIS and remote sensing in groundwater investigations: A case study in Burdur, Turkey. Hydrogeology Journal, 13: 826-834. doi: 10.1007/s10040-004-0378-5.

Talon, B., Carcaillet, C. \& Thinon, M., 1998. Études pédoanthracologiques des variations de la limite supérieure des arbres au cours de l'Holocène dans les Alpes françaises. Géographie Physique et Quaternaire, 52 (2) : 195-208. doi: $10.7202 / 004875$ ar.

Valladares, A., 2009. 9520 Abetales de Abies pinsapo Boiss. En: VV.AA., Bases ecológicas preliminares para la conservación de los tipos de hábitat de interés comunitario en España. Dirección General de Medio Natural y Política Forestal, Ministerio de Medio Ambiente, y Medio Rural y Marino, Sección Bosques, Madrid. 
Valle, F. (Ed.) 2003. Mapa de series de vegetación de Andalucía. Rueda, Madrid.

Vernet, J. L., Ogereau, P., Figueiral, I., Machado, C. \& Uzquiano, P., 2001. Guide d'identification des charbons de bois préhistoriques et récents, Sud-Ouest de l'Europe: France, Péninsule ibérique et Îles Canaries. CNRS, Paris.

Vaschalde, C. Durand, A. \& Thiriot J., 2011. Vitrification and craft fire in occidental Mediterranean. Describing characteristics, first results and research hypothesis. En: Badal, E., Carrion, Y., Grau, E., Macias, M., Ntinou, M. (eds.), Saguntum: Papeles del Laboratorio de Arqueología de Valencia, 5th
International Meeting of Charcoal Analysis; The charcoal as cultural and biological heritage, 19-20 pp. Universidad de Valencia, Valencia.

Wirthmann, A., 1970. Zur Geomorphologie der Peridotite auf Neukaledonien. Tübinger Geographische Studien, 34: 191-201.

Wirthmann, A., 2000. Geomorphology of the Tropics. Springer, Berlin.

Yusta, A., Berahona, E., Huertas, F., Reyes, E., Yáñez, J. \& Linares, J., 1985. Geochemistry of soils from peridotite in Los Reales. Acta Mineralogica Petrographica, 29: 439-498. 